\title{
Compressive Properties of SiC Particle-Reinforced Aluminum Matrix Composites under Repeated Impact Loading
}

\author{
D. F. Cao, ${ }^{\mathrm{a}, 1}$ L. S. Liu, ${ }^{\mathrm{a}, \mathrm{b}}$ Q. W. Liu, ${ }^{\mathrm{b}}$ and S. X. $\mathrm{Li}^{\mathrm{a}}$ \\ a State Key Laboratory of Materials Synthesis and Processing, Wuhan University of Technology, \\ Wuhan, China \\ b Department of Engineering Structure and Mechanics, Wuhan University of Technology, Wuhan, \\ China \\ ${ }^{1}$ Caodongf@163.com
}

Under repeated impact loading, SiC particle-reinforced aluminum matrix composites (SiCp/Al) experience severe plastic strains, which can lead to local changes in their microstructure. Microstructure variations have a significant effect on the dynamic behavior of SiCp/Al composites under subsequent impact loading. Their microstructure was analyzed by scanning electron microscopy (SEM). Then the dynamic compressive properties of SiCp/Al composites were studied using the split Hopkinson pressure bar (SHPB), and the dynamic compression stress-strain curve for each impact was plotted. The SEM results revealed that an increase in the impact cycle led to enhanced cracking of particles and interface delamination. The SHPB results showed that the yield stress and flow stress increased significantly for the first three cycles and then remained constant. The material behavior during the first three cycles can be attributed to strain hardening of the metal matrix, while its stability at the subsegnent stages is the combined effect of strain hardening of the metal matrix and damage accumulation in the composite.

Keywords: repeated impact loading, $\mathrm{SiCp} / \mathrm{Al}$ composites, microstructure, damage accumulation, strain hardening.

Introduction. Metal matrix composites reinforced by ceramic particles (MMCp) have been intensively studied worldwide. The combination of light weight, high specific strength and modulus, low thermal-expansion coefficient and good wear resistance makes MMCp very lucrative for large-scale industrial application purposes $[1,2]$. During the service life, the MMCp composites are exposed to various loading conditions. Heavy-duty conditions include repeated loading by the external impact loads, which may lead to a disastrous failure. For example, the brake pad and piston made of MMCp are subjected to repeated impact loading during their operation. Under repeated impact loadings, MMCp experience nonlinear deformations, which may lead to local changes in their microstructure and strongly affect their mechanical performance under the subsequent impact loading. In addition, the response of these composites to the repeated impacts should be clarified to improve the structural safety of the devices and ensure a longer service life.

Generally, the impact behavior of MMCp is affected by various factors, including particle clustering, particle cracking, weak matrix-reinforcement bonding, particle size, particle shape, particle distribution and particle content [3]. In spite of the intensive research of impact response of MMCp, most studies addressed the single-impact loading of specimen at different impact energy levels [3-5], instead of multiple-hit or repeated impact loading conditions. On the other hand, studies on the repeated-impact response are mainly focused on fiber-reinforced composites [6-11] or cementation composites [12] and alloys $[13,14]$. The performance of MMCp subjected to the repeated impact loading is seldom reported.

The aim of this work is to investigate the dynamic mechanical properties of $\mathrm{SiCp} / \mathrm{Al}$ composites under repeated impacts using the SHPB. The microstructure of SiCp/Al 
composites under the repeated impact loading is analyzed by SEM. Then, the dynamic compressive behavior of $\mathrm{SiCp} / \mathrm{Al}$ composites, which have undergone a single or repeated unrecoverable deformation under the previous impacts, is investigated.

\section{Experimental Details.}

1.1. Specimen Preparation. The SiCp/Al composites were prepared by the hotpressing sintering using aluminum with a purity of $99.9 \%$ and $\alpha$-SiC particles. The average size of $\mathrm{SiC}$ particles and pure aluminum powder were 13.5 and $10 \mu \mathrm{m}$, respectively. The $\mathrm{SiCp} / \mathrm{Al}$ composites with $20 \%$ volume fraction of $\mathrm{SiC}$ particles were prepared by the powder metallurgy technique $[15,16]$. The $\mathrm{SiC}$ and $\mathrm{Al}$ powders were mixed and kept for $2 \mathrm{~h}$ using the dry mixing method. The mixed $\mathrm{Al} / \mathrm{SiC}$ powders were cold-compacted in a tool steel die. The hot-pressing sintering was implemented at $650^{\circ} \mathrm{C}$ and $30 \mathrm{MPa}$ for $1 \mathrm{~h}$. The sintering process was performed in argon. After sintering, the $\mathrm{SiC} / \mathrm{Al}$ composites were subjected to hot extrusion. The $\mathrm{SiCp} / \mathrm{Al}$ composites were extruded as billets at $490^{\circ} \mathrm{C}$, whereas the extrusion reduction ratio was $2: 1$ by area. No further quenching treatment was applied to the composites. For the dynamic compression tests, the specimens were machined into short cylindrical bars of $6 \mathrm{~mm}$ in diameter and $4 \mathrm{~mm}$ in length. The slenderness ratio (i.e., the length-diameter ratio) of the specimens was approximately 0.66 , which was slightly larger than the optimized value [17]. This ratio was determined based on the fact that specimen length would be reduced, while the diameter will increase in this experiment. In this way, the slenderness ratio was expected to vary around the optimized value. In addition, the specimens were polished to minimize the measurement deviation resulting from the surface friction between specimens and the bar.

1.2. Repeated Dynamic Testing and Characterization by SEM. Repeated dynamic compressive testing was designed to obtain the dynamic stress-strain curves of $\mathrm{SiCp} / \mathrm{Al}$ composites under repeated loadings, where $\mathrm{SiCp} / \mathrm{Al}$ composites experienced plastic deformations, which could lead to local changes in their microstructure. The variation of microstructure has a significant effect on the dynamic mechanical performance of $\mathrm{SiCp} / \mathrm{Al}$ composites under the subsequent impact loading. Herein, the dynamic compressive behavior of the composite specimens, which have shown a single or repeated unrecoverable deformations under the previous impacts, was analyzed in this study.

Due to the pronounced strain-rate sensitivity of the mechanical properties of $\mathrm{SiCp} / \mathrm{Al}$ composites, as a result of the $\mathrm{SiC}$ particulates, the dynamic response of each impact at the same strain rate was compared with another one to eliminate the disturbance of the strain effect. Due to the challenges in precise control of the impact velocity of striker bar in SHPB (even if the trigger pressures of the striker bar are the same), a group of specimens was prepared and tested at the same strain rate.

In addition, the maximum strain of each impact is controlled at about $10 \%$, and the temperature softening effect can be neglected [18].

The complete experimental process was as follows:

(i) the diameters and lengths of all the specimens were measured and recorded;

(ii) the first SHPB testing was conducted for all specimens;

(iii) the diameters and lengths of all the impact-loaded specimens were measured again and one of impact-loaded specimens was used for the first SEM, while others were subjected to the next impact;

(iv) this process was repeated five more times (resulting in 6 SHPB tests in total). The stresses, strains, and strain rates of each impact are calculated via Eq. (1):

$$
\sigma=\frac{A}{A_{0}} E \varepsilon_{t}, \quad \varepsilon=-\frac{2 C_{0}}{L_{0}} \int_{0}^{t} \varepsilon_{r} d t, \quad \dot{\varepsilon}=-\frac{2 C_{0}}{L_{0}} \varepsilon_{r},
$$

where $C_{0}$ is the longitudinal wave velocity in the Hopkinson bar, $L_{0}$ is the effective length of the specimen, $E$ is the Young modulus of the Hopkinson bar, $\varepsilon_{t}$ is the 
transmitted wave, $\varepsilon_{r}$ is the reflected wave, and $A$ and $A_{0}$ are the cross-sectional areas of the Hopkinson bar and the specimens, respectively. Test details can be found in $[5,17]$.

After each impact loading, one of the loaded specimens was sectioned along the compression axis, polished and etched for microscopic examination.

2. Results and Discussion. In this section, $\mathrm{SiCp} / \mathrm{Al}$ composites under repeated impacts were characterized by SEM to investigate the microstructure evolution. The dynamic compressive curves at two strain rates (2000 and $\left.1600 \mathrm{~s}^{-1}\right)$ under repeated impacts were constructed, as well as a stress-strain curve of the single large-deformation test at the strain rate $2000 \mathrm{~s}^{-1}$.

2.1. Macroscopic Deformation and Microstructure Characteristics. The SiCp/Al composites with a $20 \%$ volume fraction of $\mathrm{SiC}$ particles exhibited ductility similar to metals. Under impact loadings, the $\mathrm{SiCp} / \mathrm{Al}$ composites exhibited plastic deformations. In the macroscopic scale, significant lateral expansion and axial compression can be observed. The diameters and lengths of the specimen at different stages of the process of repeated impact loading are listed in Table 1. Additionally, these data are used for the stress-strain calculations. The diameter and length denoted as the first impact refer to the original sizes of the specimen. As shown in Table 1, the diameter of the specimen increased while the length of the specimen decreased as the impact was repeated.

$\mathrm{T}$ a b 1 e 1

Specimen Diameter and Length at Different Loading Stages

\begin{tabular}{||c|c|c|c|c|c|c||}
\hline Impact number & $1 \mathrm{st}$ & 2nd & 3rd & 4 th & 5 th & 6 th \\
\hline Length $(\mathrm{mm})$ & 4.10 & 3.66 & 3.20 & 2.80 & 2.30 & 2.10 \\
\hline Diameter $(\mathrm{mm})$ & 5.62 & 6.20 & 6.70 & 7.20 & 8.08 & 8.30 \\
\hline
\end{tabular}
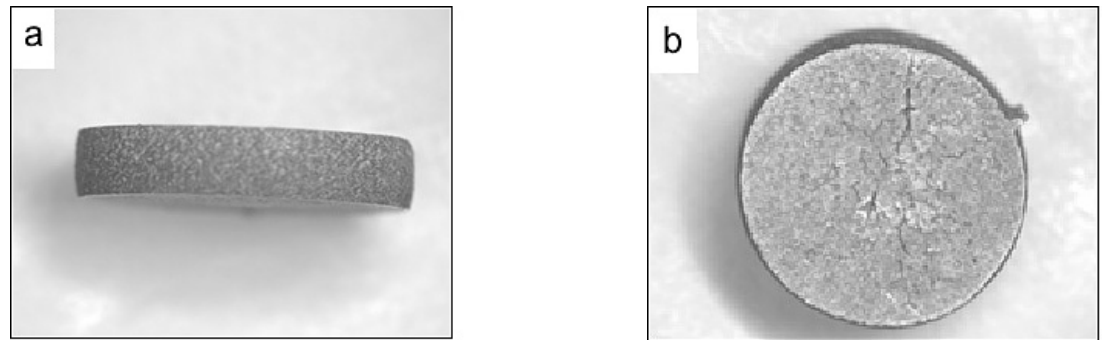

Fig. 1. Macroscopic deformation after the 6th impact: (a) lateral surface; (b) transverse surface.

Figure 1 shows the lateral and transverse surfaces of the specimen after the 6th impact. Characterization of the specimen fracture surface showed that some major cracks appeared at the transverse surface, while no visible cracks could be found at the lateral surface. This phenomenon can be explained by the theory of stressed state. In a SHPB test, the specimens are mainly subjected to a compressive loading in the axial direction, accompanied by tensile loading in the transverse direction due to the Poisson effect. For ceramic particle-reinforced metal matrix composites, the dynamic failures can be attributed to cracking of the reinforcing particles and partial debonding at the particle/matrix interface, which results in the nucleation of voids within the matrix. Indeed, cracked reinforcing particles still exhibit their compression load-bearing capability in the axial direction, but not in the transverse one. On the other hand, a partial debonding is seldom observed in the axial direction of the particle/matrix interface. As a result, in the most cases, visible cracks are usually present at the transverse surface, but not at the lateral one. 
Figure 2 shows the SEM images of different $\mathrm{SiCp} / \mathrm{Al}$ composite specimens. Characterization of the fracture surface of the composite after the 1st and 2nd impact (as shown in Fig. 2a and 2b) showed some microcracks in the large particles, while the majority of $\mathrm{SiC}$ particles remained intact. Interfacial cracks, which appeared due to a weak matrix-reinforcement bonding, can also be observed in the composites, while the share of weak-bonded particles is small. After the 4th and 5th impact (Fig. 2c and 2d), the composite specimens exhibited numerous cracked $\mathrm{SiC}$ particles, while a weak matrixreinforcement bonding was easily observed. This process is similar to that observed during the quasi-static fracture of such composites. Herein, particles contributed to the fracture process by imposing strong constraints on the matrix, thus accelerating the matrix deformation in the vicinity of these particles and increasing the stress in the matrix to an abnormally high level, which led to the matrix failure. Meanwhile, due to the higher stiffness and irregular shape of the $\mathrm{SiC}$ particles, a strong stress concentration occurred in the vicinity of the particles, resulting in particle cracking and void nucleation in the surrounding matrix. Indeed, the constraints imposed by the fractured particles on the surrounding matrix are weakened, as compared to that by intact particles, resulting in larger deformations in the matrix and lower flow stresses of the composites. Meanwhile, the accumulated damage and debonding of particles led to weakened strain-hardening effect of the matrix.
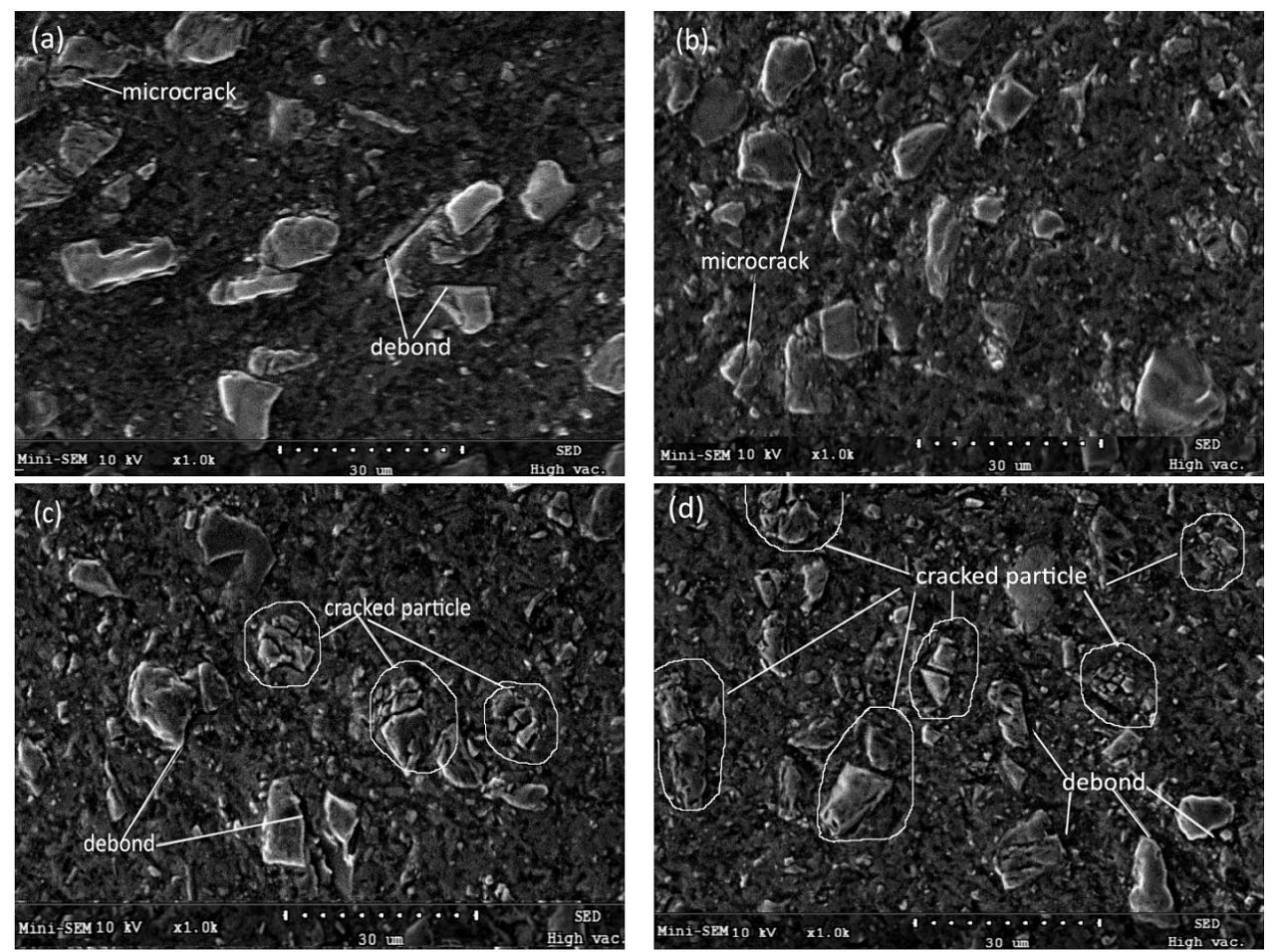

Fig. 2. SEM images of the SiC/Al composites: (a) 1st impact; (b) 2nd impact; (c) 4th impact; (d) 5th impact.

Based on the macroscopic deformation and microstructural changes induced by the repeated impacts, it can be concluded that the $\mathrm{SiCp} / \mathrm{Al}$ composite specimens experienced plastic deformation after each impact. As a result, microstructural damages were observed in the specimens, primarily in the form of reinforcement fracture and interface debonding between particles and matrix. Additionally, the damages were aggravated by repeated impacts. The plastic deformation and accumulated damage had an effect on the dynamic 
compressive behavior of composites under the subsequent impacts. In Section 2.2, the dynamic compressive mechanical curves with the number of impact at strain rates of 2000 and $1600 \mathrm{~s}^{-1}$ are discussed.

2.2. Dynamic Mechanical Properties. Based on the analysis of the strain rates, it was found that two series of strain rates (1600 and $\left.2000 \mathrm{~s}^{-1}\right)$ were intrinsic to all experimental data. Figure $3 \mathrm{a}$ and $3 \mathrm{~b}$ shows the correlation of the dynamical compressive properties of specimens and the number of impacts at strain rates of 2000 and $1600 \mathrm{~s}^{-1}$, respectively. As one can see, the impact behavior varies with the number of impacts. The first impact resulted in the lowest yield stress and flow stress, but the respective plastic hardening modulus was the maximum. As the number of impacts increased, the yield stress and flow stress increased in the first 3 cycles and saturated afterwards (also shown in Fig. 4). This can be explained by the inelastic deformation of $\mathrm{SiCp} / \mathrm{Al}$ composites at the early stages. $\mathrm{A}$ detailed analysis is presented in the following session.

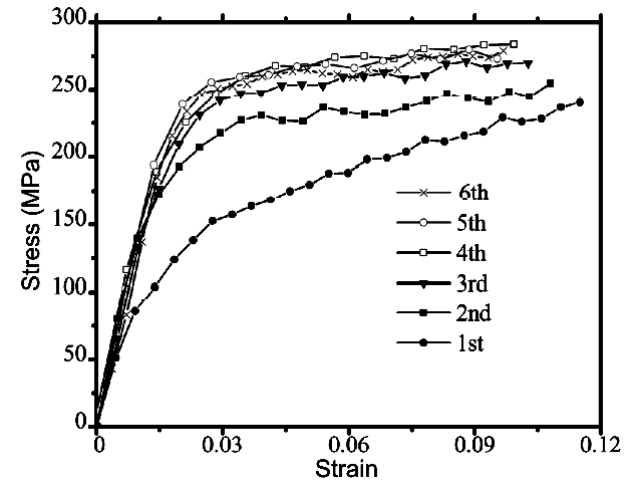

a

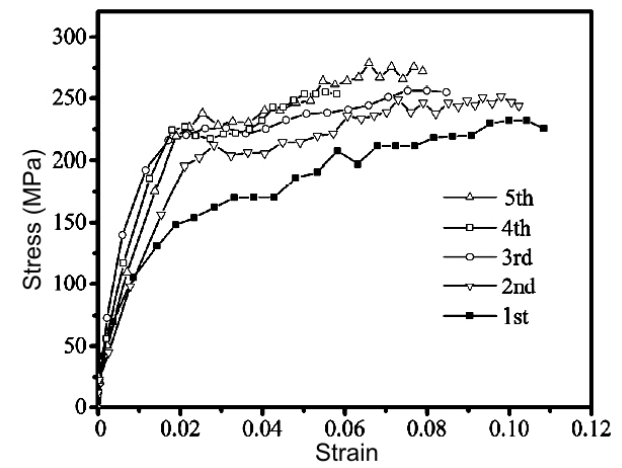

b

Fig. 3. Dynamic compressive mechanical curves with the number of impacts at strain rates 2000 (a) and $1600 \mathrm{~s}^{-1}(\mathrm{~b})$.

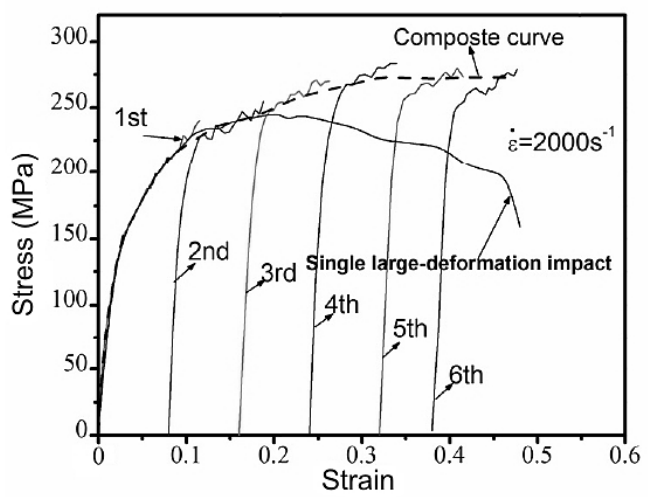

Fig. 4. Composite stress-strain curve consisting of multi-impact curves at the strain rate $2000 \mathrm{~s}^{-1}$. The corresponding stress-strain curve of the single large-deformation test at the same strain rate is also shown for comparison.

After being subjected to the first impact, the SiCp/Al composites showed a significant improvement in the dynamic flow stress and yield stress in virtue of the strain hardening of the matrix. On the other hand, the plastic hardening modulus decreased due to the weakened matrix-reinforcement bonding and cracking of the reinforcing particles as a result of the impact. As the number of impacts increased, the yield stress and flow stress 
increased further, due to the strain hardening, which was still playing a leading role, despite the accumulating internal damage within the composites. After approximately 3 impacts, a nearly stationary behavior was observed for the yield stress and flow stress. This can be explained by the balance between strain hardening and accumulated damage.

To describe completely the relationship between the stress and cumulative strain, we have superimposed six curves in Fig. 3a to get a composite stress-strain curve by fitting the flow stress curves of repeated impacts as shown in Fig. 4. This data process mode refers to the Hopkinson bar recovery experimental technique [19, 20], which has been developed and used to decouple temperature softening and strain rate effect for the materials at high strain rates. The corresponding stress-strain curve of the single large-deformation test at the same strain rate is also given for comparison. In fact, the single large-deformation test can be carried out by changing the length of striker bar in SHPB to increase the duration of input stress pulse.

By analyzing these curves, some regularities can be observed:

(i) The composite curve implies a different approach to exhibit the general trend of the flow stress during the repeated impacts, which is consistent with the regularity shown in Fig. 3a.

(ii) The yield stress is significantly less than the flow stress at the maximum strain of the previous impact. For example, the flow stress at the maximum strain of the 4th impact is about $284 \mathrm{MPa}$, while the yield stress of the 5th impact is about $257 \mathrm{MPa}$. Damage accumulation in composites is the main reason for the above trend. After each impact, the unloading process of composites includes not only the elasticity recovery, but also the variation of microstructure damage. The interface force in a cracked particle and the bonding force between the particle and matrix would be released. When the specimen is loaded again, the flow behavior of composites is affected not only by the matrix strain hardening, but also by microstructure damage variation.

(iii) In contrast to the single large-deformation SHPB test, the specimens subjected to multi-impacts show a pronounced hardening effect, although the cumulative strain is greater than 0.4. The flow stress of a single large-deformation impact is less than that of repeated impacts after approximately 2 impacts. Temperature-softening effect due to the large plastic strain may be the key reason for that. The impact process of SHPB can be approximately regarded as an adiabatic heating process, since the heat due to plastic work have no time to transfer in an extremely short time. It has been shown that nearly all plastic work during SHPB testing is converted into heat, while corrections for adiabatic heating in aluminum can be significant at high strains. The adiabatic temperature rise at $5 \%$ strain for the aluminum material is estimated to be less than $5 \mathrm{~K}$ [18]. As the deformation increases, more heat is generated and the flow stress of the composites may be affected. In contrast to the single large-deformation SHPB test, repeated tests generate just a low plastic strain under the repeated impacts, so the temperature effect can be neglected.

Conclusions. In this paper, a repeated dynamic compressive testing has been designed to construct the dynamic stress-strain curves of $\mathrm{SiCp} / \mathrm{Al}$ composites under repeated impacts using the SHPB. Under repeated impact loadings, $\mathrm{SiCp} / \mathrm{Al}$ composites experience significant plastic deformations, which may lead to a localized change in the microstructure. In addition, the effect of microstructure evolutions on dynamical mechanical performance of SiCp/Al composites under the subsequent impact loading was studied.

The following conclusions can be drawn:

1. As the impact number increases, a lateral expansion and axial compression can be observed, as well as cracks at the transverse surface.

2. According to SEM images, the $\mathrm{SiCp} / \mathrm{Al}$ composite specimens experience plastic deformation as a result of each impact, while microstructural damages occurr immediately after generation of plastic deformation. Primarily, the microstructural damages are in the 
form of reinforcement fracture and interface debonding between particles and matrix, while the microstructural damages increase with the number of impacts.

3. The yield stress and flow stress increase significantly in the first three impacts, but stay stationary afterwards.

4. The change in the impact behavior during the first three impacts is attributed to strain hardening of the metal matrix, while stationary behavior at the later stages is a result of joint action of the metal matrix strain hardening and damage accumulation in composites.

5. In contrast to the single large-deformation SHPB test, the specimens exhibit a pronounced hardening effect in multi-impact testing, although the cumulative plastic strain is greater than 0.4. This canbe attributed to the absence of temperature-softening effect due to the low plastic strain.

Acknowledgments. The work was supported by the Fundamental Research Funds for the Central Universities (WUT: 2013-1a-033 and 2013-1a-029), and National High-Tech R\&D Program of China (863 Program, No. 2012AA051104).

1. W. D. Song, J. G. Ning, and J. Wang, "Numerical simulation on tensile property of TiC particle reinforced titanium matrix composite," Mater. Res. Innovat., 15, Issue s1, s171-s174 (2011).

2. C. X. Liu, J. L. Sun, and M. H. Yao, "Addition of rare earth and diopside to improve performances of alumina matrix ceramic materials," Mater. Res. Innovat., 17, Issue 4, 293-297 (2013).

3. S. Ozden, R. Ekici, and F. Nair, "Investigation of impact behaviour of aluminium based SiC particle reinforced metal-matrix composites," Composites Part A: Appl. Sci. Manuf., 38, No. 2, 484-494 (2007).

4. Z. H. Tan, B. J. Pang, B. Z. Gai, et al., "The dynamic mechanical response of SiC particulate reinforced 2024 aluminum matrix composites," Mater. Lett., 61, No. 2324, 4606-4609 (2007).

5. L. H. Dai, L. F. Liu, and Y. L. Bai, "Effect of particle size on the formation of adiabatic shear band in particle reinforced metal matrix composites," Mater. Lett., 58, No. 11, 1773-1776 (2004).

6. V. Sivananth, S. Vijayarangan, and N. Rajamanickam, "Evaluation of fatigue and impact behavior of titanium carbide reinforced metal matrix composites," Mater. Sci. Eng. A, 597, 304-313 (2014).

7. E. Guades, T. Aravinthan, A. Manalo, and M. Islam, "Damage modelling of repeatedly impacted square fibre-reinforced polymer composite tube," Mater. Design, 47, 687-697 (2013).

8. W. A. de Morais, S. N. Monteiro, and J. R. M. d'Almeida, "Evaluation of repeated low energy impact damage in carbon-epoxy composite materials," Compos. Struct., 67, No. 3, 307-315 (2005).

9. O. S. David-West, D. H. Nash, and W. M. Banks, "An experimental study of damage accumulation in balanced CFRP laminates due to repeated impact," Compos. Struct., 83, No. 3, 247-258 (2008).

10. E. Sevkat, B. Liaw, F. Delale, and B. B. Raju, "Effect of repeated impacts on the response of plain-woven hybrid composites," Composites Part B: Engineering, 41, No. 5, 403-413 (2010).

11. J. Baucom, M. Zikry, and A. Rajendran, "Low-velocity impact damage accumulation in woven S2-glass composite systems," Compos. Sci. Technol., 66, No. 10, 12291238 (2006). 
12. J. Lai and W. Sun, "Dynamic damage and stress-strain relations of ultra-high performance cementitious composites subjected to repeated impact," Sci. China Technol. Sci., 53, No. 6, 1520-1525 (2010).

13. G. Kermouche, G. Pacquaut, C. Langlade, and J.-M. Bergheau, "Investigation of mechanically attrited structures induced by repeated impacts on an AISI1045 steel," CR Mecan., 339, No. 7-8, 552-562 (2011).

14. A. C. Sekkal, C. Langlade, and A. B. Vannes, "Tribologically transformed structure of titanium alloy (TiAl6V4) in surface fatigue induced by repeated impacts," Mater. Sci. Eng. A, 393, No. 1-2, 140-146 (2005).

15. Y. Şahin, "Abrasive wear behaviour of SiC/2014 aluminium composite," Tribol. Int., 43, No. 5-6, 939-943 (2010).

16. H. M. Zakaria, "Microstructural and corrosion behavior of $\mathrm{Al} / \mathrm{SiC}$ metal matrix composites," Ain Shams Eng. J., 5, Issue 3, 831-838 (2014).

17. H. Meng and J. Li, "Correlation between the accuracy of a SHPB test and the stress uniformity based on numerical experiments," Int. J. Impact Eng., 28, 537-555 (2005).

18. C. S. March, F. H. Cao, M. Kouzeli, and A. Mortehsen, "Quasistatic and dynamic compression of aluminum-oxide particle reinforced pure aluminum," Mater. Sci. Eng. A, 337, 202-211 (2002).

19. S. Nemat-Nasser, Y.-F. Li, and J. B. Isaacs, "Experimental/computational evaluation of flow stress at high strain rates with application to adiabatic shear banding," Mech. Mater., 17, No. 2-3, 111-134 (1994).

20. Y. Xia and Y. Zhou, "Recovery experimental techniques of tensile impact," Acta Mech. Sin., 12, No. 3, 244-50 (1996). 